\title{
'Insiderness', 'involvement' and emotions: impacts for methods, 'knowledge' and social research
}

\author{
Rachael Dobson* \\ University of Leeds
}

\begin{abstract}
This paper discusses 'insider' identity based on experiences as both social researcher and housing practitioner, drawing on Norbert Elias's 'involvement and detachment' theory. Examples from doctoral research are used to illustrate where 'involvement' influenced social research processes.

'Involvement' was highlighted by reactions during research processes and this account describes transitions towards a more 'detached' perspective. This is not to discredit emotional reactions in research stages, or to suggest that we should seek to just manage those feelings. Instead, embracing and confronting reactions helped generate substantive findings and a 'critical eye' beneficial for developing more sophisticated explanatory insights. Understanding 'involvement' is an ongoing process that the researcher constantly refines and adapts through an experiential approach to social researching.

Those complex and challenging processes touch on important issues about what constitutes knowledge, what it means to 'do' social research and how it is possible to 'be' self critical.
\end{abstract}

Keywords: involvement, insider, methods, emotions, reflexivity.

\section{Introduction}

This paper will explore how experiences as a housing practitioner influenced research processes. These processes include research 'design', 'official' fieldwork stages, ongoing analysis of 'collected' material (transcripts, notes) substantive findings and interpretation. Grounded in real-life experiences, this offers a self-critical approach to exploring 'identity'. Drawing on social theorist Norbert Elias (1987) experiences and emotional reactions will illustrate where 'involvement' influenced research processes (Aull Davies, 1999). It will be shown that reflexive analysis, in relation to identifying and understanding 'involvement', is a continuous process, which researchers can refine and adapt.

Discussion moves beyond accounts of benefits and limitations associated with 'insiderness' in research practice. The paper is careful to avoid suggestions that 
p. 184. 'Insiders', 'Involvement' and Emotions, impacts for knowledge and social research

researchers should learn to 'manage' their emotional reactions, or infantilising claims that researchers be 'hand held' through an intense time. Instead, it is suggested that researchers embrace and confront emotional reactions for substantive insight and individual development. Understanding 'involvement' is a dynamic and experiential approach, which requires continuous analysis (Elias, 1987). No 'procedure' is offered to identify how to 'be' self critical, although some suggestions are drawn from personal experiences.

First a review of existing literature will explore the sorts of privileges, constraints and theoretical insights associated with 'insiderness', 'involvement' and reflexive endeavours. Next, examples from my doctoral research will help illustrate perceived impacts for research processes associated 'involvement', in relation to working in a broad sector, specific organisation and role. It will be suggested that 'involvement', and attendant emotional reactions, influenced research decisions, choices, perspectives and 'instincts'.

\section{'Insiderness'}

Sociologists and geographers have analysed how shared experiences with research subjects constitute 'insiderness' and influence research processes (Mullings, 1999; Finlay, 2003a; Brannick and Coghlan, 2007). Claims to 'insiderness' have drawn on specific features including ethnicity, age, gender, class and family identity (Griffith, 1998; Mullings, 1999; Schoenberg and Ravdal, 2000), occupation and organisation (Jones, 1995; McHardy, 1996; Finlay, 2002; Labaree, 2002; Finlay, 2003b; Coy, 2006; Gunasekara, 2007). This paper draws on Brannick and Coghlan's (2007) conceptualisation of 'insiderness', which meant studying an organisation (as well as other organisations part of a wider sector) that a researcher had worked in.

A brief review of existing literature highlights perceived privileges and constraints associated with 'insiderness'. The 'insider' has improved and prolonged access to a social setting and its members, compared to the 'outsider' who does not have intimate knowledge of the group being researched prior to entering the field (Coy, 2006). The 'insider's' immersion in the field provides chance to interact with key informants, studying first hand, the 'environment, problems, language, rituals, and social relationships of a group of people' (Brannick and Coghlan, 2007: 64-65).

Benefits of 'insiderness' include greater awareness of where to locate information (Roseneil, 1993; Labaree, 2002; Brannick and Coghlan, 2007; Coughlan, 2007). 'Insiders' are privy to more informal discussion and gossip, being better able than 'outsiders' to sift through information to identify critical events (Coughlan, 2007). Some have identified a 'covert' aspect to the identity, with the 'insider' researcher able to lay groundwork and observe 'what is going on' in a social setting, without the researched necessarily being aware their presence (Roseneil, 1993; Labaree, 2002; Coughlan, 2007).

Individual researchers claim that the 'insider' can generate more in-depth and revealing data, because of greater potential for meaningful rapport between researcher and researched. For example, the researched may consider the researcher's identity as indicator of trust and credibility (Coy, 2006). Others contend that 'insiders' are better able to understand meaning of participants' responses due to shared terminology, jargon and phrasing (Fuller, 1995; Labaree, 2002; Gunasekara, 2007).

'Insiders' have an upper hand over 'outsiders' because of tacit and 'contextualising' information. For example, initial thoughts about researchable topics and priorities may have been developed during more informal interaction with the researched prior to 
p. 185. 'Insiders', 'Involvement' and Emotions, impacts for knowledge and social research

commencing an 'official' study or 'formal' fieldwork stages (Roseneil, 1993; Fuller, 1995; Labaree, 2002). For some, 'insiderness' represents 'triangulation', as researchers can build up a many sided picture of the research setting through observation and interviewing methods (Roseneil, 1993; McHardy, 1996).

Prolonged and more 'informal' interaction sensitizes the researcher respondents and their social world (McHardy, 1996; Coy, 2006). Those experiences generate tacit knowledge, which provides useful information for research processes. For example, Coy (2006) asserted that working with female sex workers in a professional capacity meant that she could frame interview transcripts and augment analysis with knowledge of participants' lives, relationships and thought processes, 'a privilege denied to researchers who meet the participants only in the context of an interview setting' ( $p$. 427).

Moving on from privileges, 'insiders' have also described perceived challenges and constraints associated with that identity. A common theme involves managing 'dual' identities as 'professional' and 'scholar'. Finlay (2003b) found it challenging to observe and record data about fellow occupational therapists because her researcher 'self' wanted to probe and challenge subjects, whilst her therapist 'self' desired that they perform well and remained professionally sound. Gunasekara (2007) was tempted to fill in 'gaps' in respondents' answers, feeling justified because of beliefs that he understood what respondents were 'really' getting at (p. 469).

Researchers have described a range of ways to 'manage' and further conceptualise 'insiderness'. This includes strategies drawn from psychological fields (van Heugten, 2004) and Eliasian theories about 'involvement and detachment' (Perry, et al., 2004).

Strategies associated with psychological fields include 'transference' and 'countertransference', where unconscious processes are said to structure relations between researcher, subject, and the data gathered (Devereux, 1967; Hunt, 1989; van Heugten, 2004). The researcher's task is to become attuned to 'counter-transference', which is a redirection of researcher feelings towards the researched (Devereux, 1967). Van Heugten (2004) drew on that approach upon awareness of her reactions to informants in the field. At times she judged some responses harshly and failed to identify the relevance of material.

Van Heugten's (2004) approaches were informed by intersubjectivity theory proponents Storolow, Brandchaft and Atwood's (1994) conceptualisation of transference. For those authors, 'transference' reflected how the client's perceptions of the therapeutic relationship experience were shaped by their own psychological structures and organising principles. The psychotherapist's counter transference was defined similarly as the psychotherapist's organising activity. The therapeutic relationship consisted of the interaction of the client's organising principles with those of the psychotherapist (the intersubjective field). The right or wrong of the client's or therapist's perspective couldn't be determined, but to engage in a relationship, the therapist should value and understand, shedding unhelpful aspects of his or her own organising activity to 'de-centre' (van Heugten, 2004: 209).

Researchers have also used social theory to understand and manage 'identity'. Elias's (1987) ideas about 'involvement and detachment' recognised that researchers were part of the social worlds they researched, and that their 'involvement' was inevitable for research processes. However, Elias suggested that researchers should strive to manage their 'involvement' as far as possible because high levels of 'involvement' would make more detached observation and induction of possible connections between events and phenomena more difficult, limiting scope for generating 'reality-congruent knowledge' (Quilley and Loyal, 2005: 824). Researchers could achieve 'detachment' through processes of self-regulation, which meant that one 
p. 186. 'Insiders', 'Involvement' and Emotions, impacts for knowledge and social research

could be both caught up in something ('involved') but in certain instances be able to step back (become relatively 'detached') (Kilminster, 2007).

Rather than a zero sum game between involvement or detachment, Eliasian theory suggested researchers find a 'blend' of involvement and detachment (Bloyce, 2004; Perry, et al., 2004; Srinivas, 2005; King, 2006). For example, a member of Perry, et al's., (2004) research team was 'involved' in the study's research area (sexuality). For those authors, periodic reflection in a research team environment, and consultation with external actors, brought the emotional 'attachment' of the 'involved' researcher to the surface. Identifying 'involvement' was an essential aspect of 'preserving the integrity of their research project and minimizing potential distortion' in order to generate a more 'reality-congruent' picture of subjects lives (p. 145). This didn't problematise 'involvement'. Instead, the Elisian approach sensitized the researcher to how their identity was influential for research processes, which had potential to 'minimize the costs and maximise the benefits of researcher involvement' (p. 145).

The Eliasian understanding of dynamism in identity (sometimes more involved, sometimes more detached) is found in criticisms of static positionalities like 'insider'/'outsider' (Mullings, 1999). In a persuasive argument, Mullings (1999) suggests that it is a risk for researchers to make assumptions about the researched, based on the sorts of perceived identity differences that inform ideas about 'insiderness'. An insider/outsider binary freezes positionalities in place and asserts a boundary that is "not only highly unstable but also one that ignores the dynamism of positionalities in time and through space. No individual can consistently remain an insider and few ever remain complete outsiders' (Mullings, 1999: 340).

For Mullings the term 'positional spaces' was preferable because it required that the researcher located points of connection between researcher and researched, which could engender the sort of trust and co-operation beneficial for generating 'meaningful' knowledge. Visible attributes (race, gender, ethnicity, class) and familiar boundaries ('insider'/'outsider') were challenged in favour of more 'transitory' spaces (p. 340).

This section has enabled us to move from more descriptive ideas about privileges and limitations associated with 'insiderness', towards ideas that capture a more complex and dynamic sense of 'involvement'. Next I will provide information about my practitioner experiences, to help contextualise discussion in later sections.

\section{Becoming a Practitioner and Researcher}

This section will begin to consider how specific experiences in a distinct role, organisation and sector were influential for social research processes.

For two years prior to doctoral study, I worked as a full time housing practitioner, in both front line and managerial positions, for a local authority Housing Advisory Service (hereby referred to as HAS). I worked as part of a local set of organisations conceptualised for the purposes of this paper as a 'housing related support sector' (hereby referred to as HRSS). The HRSS constituted a range of organisations who 'worked with' individuals understood by practitioners to have 'needs' that related to their ability to obtain and/or sustain accommodation.

The HAS's remit was to assess service users' entitlement to provision against statutory criteria (the Housing Act 1996, as amended 2002), and to offer specific resources (temporary accommodation, permanent re-housing) where entitlement existed. In my front line capacity I advised service users, and completed official assessments with individuals who approached the local authority for assistance, in 
order to establish if a 'duty' existed. I was promoted to manage temporary accommodation services contracted out to private providers (houses and flats supplied by private sector groups). This involved managing a small team of front line practitioners.

I opted to maintain my practitioner role on a part time basis for two years of postgraduate study and capitalised on tacit knowledge and professional networks for research purposes. My thesis explored the sorts of 'official' policies and more 'informal' processes used by HRSS practitioners to 'discipline' service user behaviour. Rather than comparing 'like for like' policies, I researched a range of HRSS 'techniques' and 'strategies' used as part of attempts to generate normative standards of behaviour. Research involved identifying practitioner 'methods' and their 'meanings'.

I was interested to explore what influenced practitioner perspectives, especially in relation to organisation environment and individual 'identity' and carried out a series of semi-structured in-depth interviews with cross rank actors from five different HRSS organisations. The sample included three 'voluntary sector' agencies and two statutory organisations. The organisations that identified themselves as 'voluntary sector' agencies included a supported housing project and two drop in centres. The statutory sector organisations included a social landlord and my organisation, the HAS. Organisations were selected on the basis of initial observations about the balance of 'enforcement' and 'support' in practices. The statutory providers had increased official enforcement policy 'tools' at their disposal in contrast to other participating organisations.

Plans were developed for 'official' fieldwork stages and a period of 'data collection'. Drawing on Yanow (2000) 'data' refers to 'the words, symbolic objects, and acts of policy-relevant actors along with policy texts, plus the meanings these artifacts have for them' and that what is 'collected' are 'the researcher-analyst's observations and interpretations (taped, noted or both) and copies of relevant documents' (p. 27). Whilst there may be a distinct period of data 'collection', Yanow identified that analytical and interpretive processes take place prior to and beyond that distinct stage. In other words, 'involvement' was ongoing, beyond data collection stages.

UK homelessness organisations have been characterised as especially diverse with variation in professional remit, funding source, regulatory frameworks, ethos and understandings of 'expertise' for practice (Seal, 2005). Hutson and Liddiard (1994) suggested that organisations' ideas about 'homelessness' are influenced by availability of resources and professional objectives. In particular, statutory providers' conceptualisations of 'homelessness' are influenced by availability of local resources (social housing stock) and interpretation of housing law (Lidstone, 1994; Burrows, et al., 1997; Lowe, 1997; Fitzpatrick and Pawson, 2007).

The role of 'agency' for housing practice focuses on processes of resistance and subversion by service users and practitioners ('gatekeepers') (Harrison, 2001). For example, Lipsky's (1997) 'street-level bureaucracy' theorised that attempting to respond to service users on mass basis would manifest in practitioners giving in to favouritism and stereotyping. Activity would reflect organisation, as opposed to service user, requirements. Although the theory has been subject to criticism for it's focus on the base of an organisation (Jeffers and Hoggett, 1995). Lipsky's insights remain persuasive for those with practitioner experience of front line work in high demand ‘human service' organisations.

In my HAS role there was requirement to respond to service users within a high demand and time constrained environment. Provision was highly conditional, with entitlement to resources based on local authority interpretation of statutory criteria (housing law 1996, as amended 2002) (Lowe, 1997). Assessment strategies required 
p. 188. 'Insiders', 'Involvement' and Emotions, impacts for knowledge and social research

that practitioners analyse service user accounts, sorting 'fact' from 'fiction' in order to (dis)prove entitlement to statutory resources, within an official remit to protect public funds (Garot, 2005). What was it about these experiences, which was relevant for social research processes?

First, practitioner experiences seemed influential for research planning stages. My 'involvement' encouraged me to develop research methods informed by my 'instincts' for what constituted 'meaningful' knowledge. Second, emotional reactions throughout research processes, indicated that experiences of a broad sector, a distinct organisation, and specific role, were influential. Before exploring those points, the next section will briefly consider why this sort of self-critical account is important.

\section{Writing a reflexive account}

In recent years the social research community has witnessed a growth in literature around 'reflexive' thinking (cf. Mason, 2002), which has asserted the researcher's voice and their 'presence'. 'Being' reflexive can involve exploring our reactions to research processes. How and in what ways are our reactions informed by specific experiences? How might our 'selves' as researchers influence substantive findings? Understanding what might underpin specific reactions can provide insights that are beneficial for substantive findings.

'Being' reflexive goes to the heart of epistemological and ontological assumptions around what constitutes 'meaningful' knowledge, which reflects debates about 'quality' and 'validity' in social research. Reflexivity is 'post-positivist' in foundation; a departure from claims that emotional involvement in research is a hindrance to objectivity and neutrality (Hunt, 1989). Policy research cannot be conducted from a position external to what is being studied because the very presence of the researcher influences what is being observed (Yanow, 2000). This centralises the researcher by recognising that material (ideas, 'data', analysis) is generated through that individual. Acknowledging this enables us to consider that another researcher in a different relationship to the researched might 'unfold a different story' (Finlay, 2002: 531).

Reflexive approaches are informed by a social constructionist paradigm, which understands that findings represent 'meanings' negotiated by researcher and researched in a specific social context (Holstein and Gubrium, 1995). From that perspective there can be multiple interpretations of the same event and that the task (and challenge) for the social researcher is to reveal those different voices (Yanow, 2000). For that reason the term 'bias' is considered innapropriate because it implies an unequivocal reality distorted by a researcher's subjective interpretation (Finlay, 2002).

However, although claims to researcher neutrality might be implausible (Holstein and Gubrium, 1995), they are not unproblematic. Although benefits associated with 'being' and 'doing' self-critical reflexive accounts include claims to authenticity, credibility and quality for both the individual researcher and substantive findings, Finlay (2002) argues that it is useful to identify how far, and in what ways, the researcher might influence their research. This can involve the researcher reflecting on the topic for study and their own relationship to that topic, to examine their motivations and interests in the area under study (p. 536). Moreover, examining painful reactions to research processes is thought to generate analytical awareness with personal revelation a 'springboard' for substantive insight and interpretation (Finlay, 2003a: 8). By exposing contextual information, such as a researcher's existing values and 
p. 189. 'Insiders', 'Involvement' and Emotions, impacts for knowledge and social research

experiences, to the prejudgements of others, the research audience is considered better able to judge the credibility of research (Roseneil, 1993; Gunasekara, 2007).

There are constraints and limitations to reflexive accounts. First, attempting to reflexively account for activities is claimed to result in never ending circles, as each account becomes subject to further analysis (Seale, 1999). Second, some have called for more 'rigorous' measures to ensure quality in qualitative research. Examples include counting the number of times a specific theme appears, using conversational analysis techniques to decipher 'meaning' from transcripts, and seeking cases that deviate from the researcher's initial hypothesis (Seale and Silverman, 1997; Seale, 1999; Li and Seale, 2007). Third, excessive focus on the individual researcher could be at the expense of identifying alternative factors that have helped generate the research account (Finlay, 2002). Fourth, the capacity of an individual researcher to retrospectively account for the research process is questioned. Indeed, writing 'sewn up' acounts of former experiences and thought processes might seem counter-intuitive to social researchers more familiar with the 'messiness' of social research, and attendent challenges associated with 'wrestling'1 rich qualitative data to the ground.

In recognition of those various limitations, a reflexive self-critical account should exercise caution. At it's very best, this type of exercise provides a partial and tentative analysis; one version of 'reality' that seems to work at that moment (Finlay, 2002; Finlay, 2003b). The following section, which describes experiences and emotional reactions throughout fieldwork stages, is mindful of that perspective.

\section{Experiences}

Decisions and choices throughout research processes were informed by a range of emotional reactions, which appeared to reflect my 'involvement'. I want to argue that seeking to understand those reactions generated substantive insights, and has assisted my ongoing development as a social researcher.

Analysis of specific events indicated broad impacts of 'involvement' for research processes. First, in the run up to 'official' fieldwork stages and informed by 'instinct' more than explicit planning, I developed participant observation activities, through the development of a shadowing exercise. This suggested that my ideas about what constituted 'meaningful' knowledge, and where I could locate this, were shaped by practitioner experiences. Second, research aims required that I identify multiple voices, their methods and meanings. I want to argue that my practitioner experiences of broad sector, a particular organisation and a distinct role, presented a 'risk' for substantive findings because in specific instances I struggled to 'hear' certain accounts and to maintain a 'critical eye'.

\section{'Meaningful' knowledge}

Embarking on interviews with key actors, without the sorts of contextual information generated through my practitioner experiences somehow felt 'dry'. This indicated that I conceived benefits associated with 'immersion' in the field. Informal conversations with research subjects throughout my practitioner role had provided relevant tacit information that could be worked into interviews, analysis and later writing stages.

In response to those instincts, I developed an informal shadowing exercise. This enabled me to spend a few days in each participating organisaton as a researcher. Participating with the researched to highlight the obvious, given or natural is synonomous with benefits accorded to participant observation and ethnographic methods (Pollner, 1987; Gerson and Horowitz, 2002). Organising more prolonged 
interaction with key actors in their organisations felt instinctively useful for better understanding and sensitizing me to informants' experiences, 'realities' and social worlds.

\section{Acknowledging multiple voices}

Practitioner experiences appeared to generate urges for 'fact finding' or 'truth seeking' behaviour. I would be inclined to 'check' respondent accounts against my own 'information' and understandings based on experiences within a specific organisation and practitioner role. Specific experiences during the shadowing exercise suggested that my statutory 'upbringing' in the HAS was especially influential for research processes.

Former experiences of questioning service user responses, associated with my former role, reinforced moves to discredit service user accounts in all organisations. Institutional culture and associated tensions between organisations in the HRSS and allied fields (Oldman, 1998; Shaw, Lambert et al., 1998) encouraged me to problematise individual informants in participating voluntary sector organisations. I also felt loyalty towards the HAS. Knowledge of individuals there and operational processes seemed to drive practices of 'second guessing' and suspicion towards specific practitioner and service user accounts.

In one example, informants claimed that the HAS had denied resources to a service user demonstrating visible 'vulnerabilities', which included pregnancy and self-harm. I found myself 'double checking' these accounts against what I was aware 'should happen'. In another example, I met service users who claimed that the local authority had done 'nothing' for them. I entered into conversation, aware of an instinct to 'unravel' their 'tale' using knowledge of HAS organisation procedure and rights under housing legislation. This 'pursuit of truth' detracted from exploring multiple voices and perspectives.

My 'involvement' in relation to a distinct role seemed to underpin my tendency to 'discredit' voices. Experiences in a managerial role seemed influential for urges to disregard specific perspectives and suppress their relevance for research processes. As a manager, and through maintaining relationships with managers, I was privy to informal and 'off the record' comment and gossip. That informal chat incorporated perceptions of individual front line workers' 'difficult' behaviour. For my first HAS interview, I met with a front line informant described by former managerial colleagues as 'difficult' in part because the worker 'didn't like change'.

During the interview, the worker described managerial requirements of front line workers to meet targets as a form of 'bullying' in specific instances. My initial instinct was to discredit the practitioner as someone who was 'difficult' and less open to 'change'. I was convinced that the informant was acting in self-interest, by working against processes beneficial for the 'customer'. Later on, critical discussion with academic peers encouraged me to think about my reactions. Why was I seeking to both defend and discredit certain accounts? This helped me to move from asserting specific 'truths', towards being more open to multiple interpretations and perspectives.

In a final example, my reaction to an ethical dilemma helped illustrate practices of 'truth seeking' and 'fact finding' behaviours. Working in practitioner and researcher roles encouraged me to view daily activities through an 'academic lense'. Although my practitioner role provided enormous stimulus, it also resulted in feelings of 'saturation', which affected my ability to develop and maintain critical focus. 'Hoovering' up or and feeling 'swamped' with information became problematic. 


\section{p. 191. 'Insiders', 'Involvement' and Emotions, impacts for knowledge and social research}

For example, when shadowing in a drop in centre, I encountered a pregnant service user. Practitioners there claimed that the individual had no official involvement by welfare professionals and that the local authority was unhelpful. Given my access to official documentation as a HAS practitioner, there was a temptation to look into official records to find out 'what was really going on'.

That experience generated a fresh set of questions around ethical issues associated with multiple identities as 'researcher' and 'practitioner'. I could abuse power (within both identities) and confidentiality by 'checking' records. That 'dilemma' encouraged me to think about why I wanted to seek 'the truth', and helped focus my role and purpose as a social researcher. I would suggest that my role as social researcher was to identify multiple voices and their 'meanings' (Yanow, 2000). Multiple accounts (and tensions between them) provided rich data. They were not 'problems' for me to 'solve' and my urge to do so was driven, in part at least, by my 'involvement'. Seeking understanding of emotional reactions (a 'dilemma') provided substantive insights about what it meant to 'do' and 'be' a social researcher.

\section{Generating a critical eye}

Practitioner experiences of a broad sector seemed to encourage tendencies to 'empathise' with my research subjects. As a HRSS practitioner, I felt 'empathic' towards the sorts of practices that I witnessed and that were reported to me by respondents. Shared experiences of operating in a particular institutional culture, and of 'working with' (disciplining) service user behaviour (Peckover, 2002) meant that I sometimes struggled to record and analyse events and issues relevant for substantive findings. My 'involvement' seemed to compromise my ability to be critical in approach in early research stages. My reactions to experiences during the shadowing exercise and initial fieldwork stages helped demonstrate where I would struggle to identify certain processes.

Informant perspectives and practices were part of an 'everyday reality' that I understood. Practitioner responses incorporated description of 'service users'. The sort of language used by informants was conceptualised for the purposes of the thesis as a 'sector speak', which existed in all participating organisations. The development of that term was informed by recent studies of New Labour discourse (Fairclough, 2000), alongside analysis of more enduring themes of 'care and control' associated with social welfare sector practices (Hunter, 2003). 'Sector speak' reflected, amongst other things, distinctive terms that were used by practitioners to describe service users 'needs' and their attendant behaviour (cf. Fopp, 1996). This included ideas about 'support needs', 'chaotic' behaviour and service users' 'capacity' to 'engage' with provision. As practitioner I also used this sort of language. In early research stages I became aware of the ubiquity of 'sector speak' through informants' responses and this became a point of analysis.

I found that I struggled to record and analyse practices, judging certain processes as a 'necessary' part of HRSS life because of views that I shared with informants about perceived operational constraints and conceptualisations of service user 'need' and attendant behaviours. Two examples helped illustrate how practitioner experiences in a broad institutional culture 'risked' substantive findings.

In the HAS, informant responses highlighted a range of informal tactics used to 'test' service users' 'desperateness' for certain accommodation types, in part to protect rationed resources like social housing (Clapham and Kintrea, 1986; Lidstone, 1994; Jeffers and Hoggett, 1995; Fitzpatrick and Jones, 2005). Where service users were entitled to temporary accommodation individual practitioners would offer hostel accommodation first, instead of a 'normal' property dispersed in a local area. Some 
p. 192. 'Insiders', 'Involvement' and Emotions, impacts for knowledge and social research

practitioners offered dispersed accommodation in an area that practitioners understood service users would not wish to stay in. Whilst recognising these practices as informal processes (as opposed to 'official' organisation policy), I felt understanding towards practitioner motivations, and struggled to shed critical light on that issue in initial research stages.

In another example, I empathised with motivations of practitioners in all organisations to 'help' service users using 'containment' practices based on their ideas about perceived 'need' and attendant behaviour(s). During the shadowing exercise I listened to individual practitioners who questioned shifts to 'direct payments', which meant benefit money was paid direct to service users. This required that service users be responsible for weekly rent payment. Failure to pay rent risked eviction from supported housing provision.

Practitioner ideas about service user 'need' and attendant behaviour(s) suggested that there were challenges associated with ensuring rent payment. For example, individual workers claimed that service users with addictions would spend their benefit money on alcohol or drugs instead of rent. In that instance, practitioners' desire to maintain control over service users' finances was a way to 'protect' service users by maintaining their shelter and 'engagement' with HRSS resources. Initially, rather than citing those responses as examples of 'voices', 'methods' and 'meanings', I struggled to shed critical light on practice 'realities'. In part this was because I identified with practitioner beliefs around how it was possible and useful to 'help' service users through containment processes.

\section{Considerations and Conclusions}

On approaching the field, ideas about what constituted 'knowledge', and where this could be meaningful located, came into focus. Strategies were developed in response to those instincts, which reflected perceived benefits for research associated with long term 'immersion' in my organisation. A range of events seemed to illustrate further where my experiences were influential for research processes. In particular, 'working with' service users with 'needs' and attendant behaviour(s) and working in specific roles for the HAS informed choices and reactions during research processes. Reactions included 'empathy' for certain views and being less open to 'hearing' certain voices. In early data collection stages I didn't always critically analyse practitioner approaches, and I railed against distinct perspectives.

Yet this self-critical account suggests that I was able to identify my 'involvement' in particular instances, and develop a more 'critical eye'. For example, I later conceptualised practitioner 'support' as practices to 'discipline' service user behaviour towards normative standards. I also conceptualised a 'sector speak'. What happened?

I want to argue that my experiences reflect transition from a more 'involved' position (Elias, 1987) and that these transitions themselves helped generate substantive findings and explanatory insights. Growing awareness of how my practitioner experiences were problematic developed in response to emotional reactions during research processes. Alongside these reactions, I was increasingly subject to critical feedback from the researched, practitioner and research peers, and more established scholars (my supervisors and growing academic networks). Critical 'lapses' were picked up, my analysis countered and opinions challenged. Explanatory insights, and guidance for other researchers with similar experiences, go beyond recommendations to 'manage' emotions or to regard reactions as just human responses to fresh encounters. Instead, it is suggested that uncertainty, intensity and 
p. 193. 'Insiders', 'Involvement' and Emotions, impacts for knowledge and social research

confusion during research processes might reflect 'involvement'. Attending to reactions can aid individual researchers' development as critical and thinking actors.

Embracing, confronting and seeking to understand both comfortable and more painful emotional reactions can help the researcher toward explanatory insights in relation to substantive themes. For example, my acute discomfort with, and desire to dismiss 'targets as bullying', encouraged me to explore transformations in welfare systems, and the role of managerialist discourses (Clarke and Newman, 1997). In contrast, thinking about my relative comfort with a 'sector speak' and practices of containment encouraged me to explore the role of 'care and control' for social welfare professions (Hunter, 2003). Identifying and understanding reactions was often sparked by engagement with academic literature and critical forum, and attention and respect for my personal instincts and emotions.

'Being' self critical is an ongoing process, which recognises that the researcher's 'involvement' is dynamic and changing. I therefore continue to value experiences that provide inspiration, stimulus, and personal reactions to unravel. Whilst acknowledging limitations of this type of reflexive approach (Finlay, 2002; Finlay, 2003b), this paper reflects a commitment to critical development through experiential learning.

\section{Acknowledgements}

I would like to thank Ryan Powell for his highly constructive feedback on a first draft of this paper. Dr Shona Hunter, Professor Tess Lea, Professor Helen Sullivan, and Professor Malcolm Harrison provided inspiration, stimulus, discussion and insights that contributed to the development of the paper.

\section{Notes}

1 In conversation with Professor Tess Lea, Charles Darwin University, Sydney, Australia, May 2009.

* Correspondence Address: Rachael Dobson, University of Leeds, Department of Sociology and Social Policy, Leeds, LS2 9JT. Email: r.dobson00@leeds.ac.uk.

\section{References}

Aull Davies, C. (1999) Reflexive Ethnography; a guide to researching self and others. London: Routledge.

Bloyce, D. (2004) Research is a messy process, A case study of figurational sociology approach to conventional issues in social science research methods. Graduate Journal of Social Science, 1, 1, 144-166.

Brannick, T. and Coghlan, D. (2007) In Defense of Being "Native"; The Case for Insider Academic Research. Organizational Research Methods, 10, 1, 59-74.

Burrows, R., Pleace, N. and Quilgars, D. Eds. (1997) Homelessness and social policy. London: Routledge.

Clapham, D. and Kintrea, K. (1986) Rationing, choice and constraint: the allocation of public housing in Glasgow. Journal of Social Policy, 15, 1, 51-67.

Clarke, J. and Newman, J. (1997) The Managerialist State. London: Sage. 
p. 194. 'Insiders', 'Involvement' and Emotions, impacts for knowledge and social research

Coughlan, D. (2007) Insider action research doctorates: Generating actionable knowledge. Higher Education, 54, 293-306.

Coy, M. (2006) This Morning I'm A Researcher, This Afternoon I'm An Outreach Worker: Ethical Dilemmas in Practitioner Research. International Journal of Social Research Methodology, 9, 5, 419-431.

Devereux, G. (1967) From Anxiety to Method in the Behavioural Sciences. The Hague, Mouton \& Co.

Elias, N. (1987) Involvement and detachment / Norbert Elias ; German editor, Michael Schröter; translated by Edmund Jephcott. Oxford: Basil Blackwell.

Fairclough, N. (2000) New Labour, New Language? London: Routledge.

Finlay, L. (2002) "Outing" the Researcher: The Provenance, Process and Practice of Reflexivity. Qualitative Health Research, 12, 4, 531-545.

Finlay, L. (2003a) The reflexive journey: mapping multiple routes, in: L. Finlay and B. Gough, Reflexivity: a practical guide for researchers in health and social sciences. Oxford: Blackwell Science, pp. 3-20.

Finlay, L. (2003b) Through the looking glass: intersubjectivity and hermeneutic reflection, L. Finlay and B. Gough, Reflexivity: a practical guide for researchers in health and social sciences. Oxford: Blackwell Science, pp. 105-119.

Fitzpatrick, S. and Jones, A. (2005) Pursuing Social Justice or Social Cohesion?: Coercion in Street Homelessness Policies in England. Journal of Social Policy, 34, 3, 389-406.

Fitzpatrick, S. and Pawson, H. (2007) Welfare Safety Net or Tenure of Choice? The Dilemma Facing Social Housing Policy in England. Housing Studies, 22, 2, 163182.

Fopp, R. (1996) No Where to Go: an analysis of the supported accommodation assistance program. Australian Journal of Social Issues, 31, 2, 209-222.

Fuller, R. and Petch, A. (1995) Practitioner research: the reflexive social worker. London: Open University Press.

Garot, R. (2005) Bias Forged Through Suspicion: The Gatekeeper in Public Housing Reconsidered. Sociology of Crime, Law and Deviance, 6, 77-105.

Gerson, K. and Horowitz, K. (2002) Observation and Interviewing: Options and Choices in Qualitative Research, in: T. May, Qualitative Research in Action. London: Sage, pp. $199-224$.

Griffith, A. (1998) Insider/Outsider: Epistemological Privilege and Mothering Work. Human Studies, 21, 361-376.

Gunasekara, C. (2007) Pivoting the centre: reflections on undertaking qualitative interviewing in academia. Qualitative Research, 7, 461-475.

Harrison, M.L. (2001) Housing social policy and difference : disability, ethnicity, gender and housing. Bristol: Policy.

Holstein, J.A. and Gubrium, J.F. (1995) The Active Interview. London: Sage.

Hunt, J.C. (1989) Psychoanalytic Aspects of Fieldwork. London: Sage.

Hunter, S. (2003) A Critical Analysis of Approaches to the Concept of Social Identity in Social Policy. Critical Social Policy, 23, 3, 322-344.

Hutson, S. and Liddiard, M. (1994) Youth Homelessness. Basingstoke: Macmillan.

Jeffers, S. and Hoggett, P. (1995) Like Counting Deckchairs on the Titanic - a Study of Institutional Racism and Housing Allocations in Haringey and Lambeth. Housing Studies, 10, 3, 325-344.

Jones, R.S. (1995) Uncovering the hidden social world: insider research in prison. Journal of Contemporary Criminal Justice, 11, 2, 106-118.

Kilminster, R. (2007) Norbert Elias: post-philosophical sociology. Abingdon: Routledge.

King, C. (2006) Documentary Analysis of the Press: Problems of Involvement and Detachment for inexperienced researchers. Graduate Journal of Social Science, $3,2,81-87$. 
p. 195. 'Insiders', 'Involvement' and Emotions, impacts for knowledge and social research

Labaree, R.V. (2002) The risk of 'going observationalist': negotiating the hidden dilemmas of being an insider participant observer. Qualitative Research, 2, 1, 97122.

Li, S. and Seale, C. (2007) Learning to Do Qualitative Data Analysis: An Observational Study of Doctoral Work. Qualitative Health Research, 17, 10, 1442-1452.

Lidstone, P. (1994) Rationing housing to the homeless applicant. Housing Studies, 9, 4, 459-472.

Lipsky, M. (1997) Street-level bureaucracy: an introduction, in: M. Hill, The policy process: a reader. London: Prentice Hall/Harvester Wheatsheaf.

Lowe, S. (1997) Homelessness and the Law, in: R. Burrows, N. Pleace and D. Quilgers, Homelessness and Social Policy. London: Routledge, pp. 19-34.

Mason, J. (2002) Qualitative Research (2nd ed.). London: Sage.

McHardy, C. (1996) Being a Teacher-Researcher: Issues of Insider Participant Teacher Research Methodology. Emotional and Behavioural Difficulties, 1, 2, 3-14.

Mullings, B. (1999) Insider or outsider, both or neither: some dilemmas of interviewing in a cross-cultural setting. Geoforum, 30, 337-350.

Oldman, C. (1998) Joint Planning - Why Don't We Learn from the Past?, in: I. Shaw, S. Lambert and D. Clapham, Social Care and Housing. London: Jessica Kingsley, pp. 32: 63-80.

Peckover, S. (2002) Supporting and Policing Mothers: an analysis of the disciplinary practices of health visiting. Nursing Theory and Concept Development or Analysis, 38, 4, 369-377.

Perry, C., Thurston, M. and Green, K. (2004) Involvement and Detachment in Researching Sexuality: Reflections on the Process of Semistructured Interviewing. Qualitative Health Research, 14, 1, 135-148.

Pollner, M. (1987) Mundane Reason: Reality in everyday and sociological discourse. Cambridge: Cambridge University Press.

Quilley, S. and Loyal, S. (2005) Eliasian Sociology as a 'Central Theory' for the Human Sciences. Current Sociology, 53, 5, 807-828.

Roseneil, S. (1993) Greenham revisited: researching myself and my sisters, in: D. Hobbs and T. May, Interpreting the field: accounts of ethnography. Oxford: Clarendon Press, pp. 177-208.

Schoenberg, N.E and Ravdal, H. (2000) Using vignettes in awareness and attitudinal research. International Journal of Social Research Methodology, 3, 1, 63-74.

Seale, C. (1999) The quality of qualitative research. London: SAGE.

Seale, C. and Silverman, D. (1997) Ensuring Rigour in Qualitative Research. European Journal of Public Health, 7, 4, 379-384.

Shaw, I., Thomas, S. and Clapham, D. Eds. (1998) Social Care and Housing. Research Highlights in Social Work. London: Jessica Kingsley.

Srinivas, N. (2005) Cultivating Sociological Detachment through Reflexivity: Response to Quilley and Loyal. Current Sociology, 53, 5, 835-841.

Storolow, R.D., Atwood, G.E., and Brandchaft, B. (1994) The Intersubjective Perspective. Northwale, N.J., Jason Aronson.

van Heugten, K. (2004) Managing Insider Research: Learning from Experience. Qualitative Social Work, 3, 2, 203-219.

Yanow, D. (2000) Conducting Interpretive Policy Analysis. London: Sage. 